\title{
Leukotriene biosynthetic enzymes as therapeutic targets
}

\author{
Jesper Z. Haeggström
}

Department of Medical Biochemistry and Biophysics, Division of Chemistry 2, Karolinska Institutet, Stockholm, Sweden.

\begin{abstract}
Leukotrienes are powerful immune-regulating lipid mediators with established pathogenic roles in inflammatory allergic diseases of the respiratory tract - in particular, asthma and hay fever. More recent work indicates that these lipids also contribute to low-grade inflammation, a hallmark of cardiovascular, neurodegenerative, and metabolic diseases as well as cancer. Biosynthesis of leukotrienes involves oxidative metabolism of arachidonic acid and proceeds via a set of soluble and membrane enzymes that are primarily expressed by cells of myeloid origin. In activated immune cells, these enzymes assemble at the endoplasmic and perinuclear membrane, constituting a biosynthetic complex. This Review describes recent advances in our understanding of the components of the leukotriene-synthesizing enzyme machinery, emerging opportunities for pharmacological intervention, and the development of new medicines exploiting both antiinflammatory and pro-resolving mechanisms.
\end{abstract}

\section{Introduction}

Leukotrienes are, as the name indicates, mainly biosynthesized by leukocytes from the myeloblastic (neutrophils, eosinophils, and mast cells) and monoblastic lineages (monocytes/ macrophages). These lipid mediators act in a paracrine manner, exerting their functions at nanomolar concentrations and causing different responses according to the target cell type (1). There are two classes of leukotrienes: the dihydroxy fatty acid leukotriene $\mathrm{LTB}_{4}$, and the so-called cysteinyl-leukotrienes (cys-LTs), comprising the lipid-peptide conjugate $\mathrm{LTC}_{4}$ and its metabolites $\mathrm{LTD}_{4}$ and $\mathrm{LTE}_{4}$, which are formed by sequential peptidolytic cleavage. Leukotrienes signal through two sets of GPCRs: BLT1 and BLT2 for $\mathrm{LTB}_{4}$, and CysLT1, CysLT2, and CysLTE, also known as gpr99, for cys-LTs (2). Classical bioactions of LTB $_{4}$ include chemotaxis, endothelial adherence, and activation of leukocytes, while cys-LTs in particular, $\mathrm{LTD}_{4}$ - contract smooth muscles in the microcirculation and respiratory tract. In addition, a spectrum of other bioactions exerted by leukotrienes have been reported, all of which support proinflammatory and immune-regulating functions of these mediators, and which have qualified the biosynthetic enzymes as potential drug targets $(1,3,4)$.

Leukotrienes are synthesized from the omega- 6 polyunsaturated fatty acid arachidonic acid (AA), which is liberated intracellularly from membrane phospholipids by several phospholipase $\mathrm{A}_{2}$ enzymes ( $\mathrm{PLA}_{2} \mathrm{~s}$ ), especially cytosolic PLA2 $\alpha$ (cPLA2 $\alpha$ ) (5). The central enzyme in cellular leukotriene biosynthesis, 5-lipoxygenase (5-LOX), requires a set of stimulatory factors for full activity and is supported by two accessory proteins, 5-lipoxygenase-activating protein (FLAP) and coactosin-like protein (CLP) (6). The catalytic iron center of activated 5-LOX converts AA in a two-step concerted reaction: first a dioxygenation into 5(S)-hydroperoxy-6-trans-8,11,14-

Conflict of interest: JZH owns stock in Pfizer Inc. and Bayer AG. Reference information: / Clin Invest. 2018;128(7):2680-2690. https://doi.org/10.1172/JCI97945 cis-eicosatetraenoic acid [5(S)-HpETE], followed by dehydration to yield the transient epoxide intermediate $\mathrm{LTA}_{4}$, a step that is referred to as the enzyme's LTA 4 synthase activity (7). Depending on the presence and functional coupling of 5-LOX to downstream enzymes, LTA $_{4}$ is further converted into the dihydroxy acid LTB by LTA $_{4}$ hydrolase (LTA4H), while LTC $_{4}$ synthase (LTC4S) conjugates LTA with glutathione (GSH) to form $\mathrm{LTC}_{4}$, the parent compound of the cys-LTs $\mathrm{LTC}_{4}, \mathrm{LTD}_{4}$, and LTE 4 . 5-LOX subcellular localization and association with FLAP and CLP play a central role in the regulation of leukotriene production (Figure 1). Before activation, 5-LOX can be located either in the cytosol or in the nucleus of the cells, depending on the cell type and the cellular environment (reviewed in ref. 8). Both cytosolic and nucleoplasmic 5-LOX moves to the nuclear envelope upon cell stimulation by various agonists, and this process is accompanied by leukotriene generation (9).

The enzymes in leukotriene biosynthesis are biochemically diverse; some are cytosolic monomeric enzymes (cPLA2 $\alpha, 5$-LOX, and LTA4H), while others are trimeric integral membrane proteins (FLAP, LTC4S, and MGST2). Together they encompass three distinct enzyme classes: hydrolases (cPLA2 $\alpha$ and LTA4H), oxidoreductases (5-LOX), and transferases (LTC4S and MGST2). In this Review, work deciphering the molecular mechanisms of leukotriene biosynthesis will be described along with recent reports on new potential therapeutic applications of drugs interfering with the production of these lipid mediators. Moreover, benefits and drawbacks with various pharmacological strategies will be discussed.

\section{5-LOX at the center stage} of leukotriene biosynthesis

5 -LOX is primarily found in various myeloid cells, including polymorphonuclear leukocytes (PMNs), monocytes/macrophages, dendritic cells, mast cells, and B lymphocytes (6). Aberrant expression of 5-LOX has been detected in many tumor cells of nonmyeloid origin (10-13). Moreover, CMV infection can induce 5-LOX expression and $\mathrm{LTB}_{4}$ production in vascular smooth muscle cells (14). 


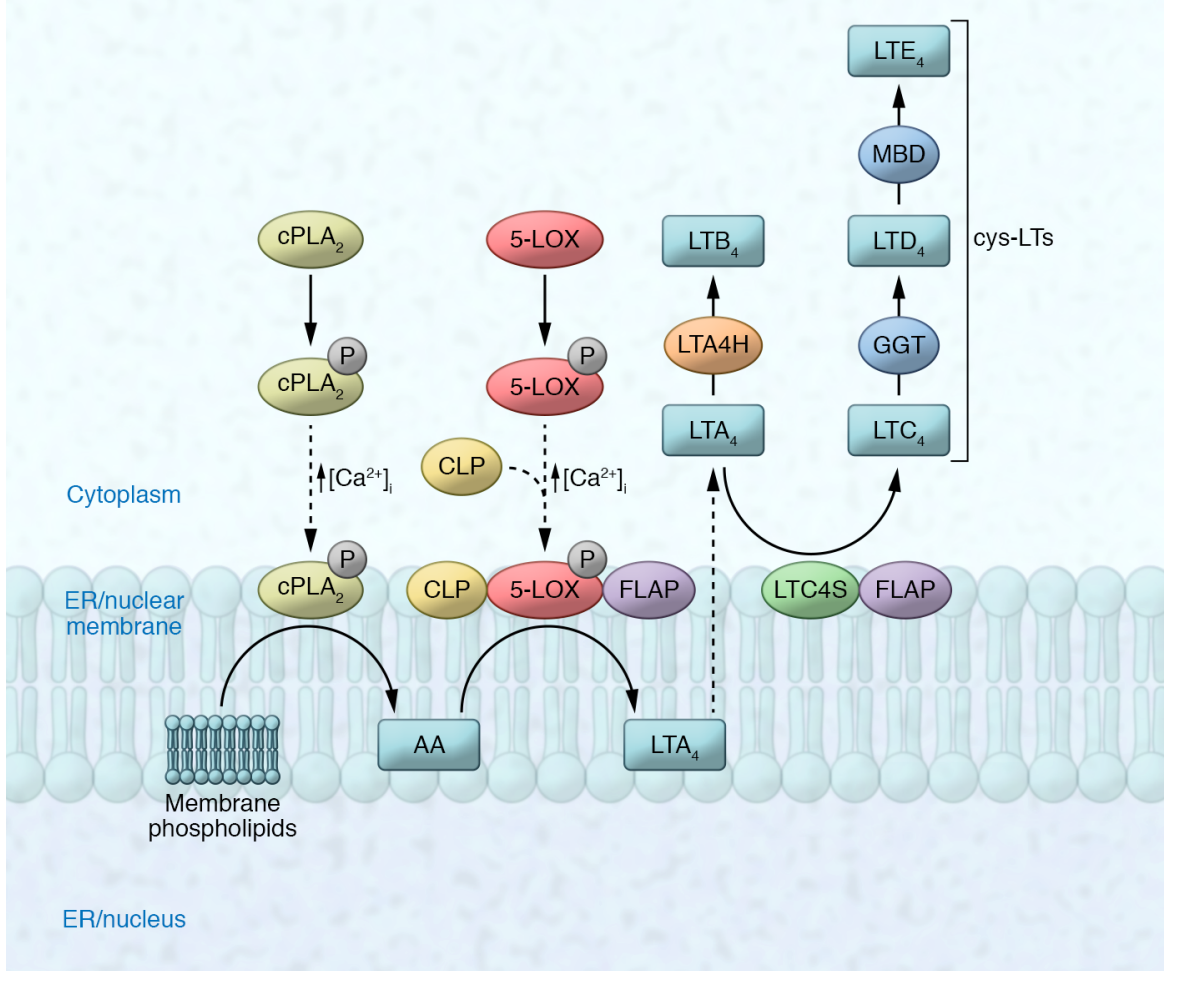

Figure 1. Translocation and assembly of the leukotriene biosynthetic complex. Schematic model for translocation of CPLA, and 5-LOX, together with CLP, to the ER and perinuclear membrane, where they meet up with FLAP and LTC4S. LTA4H stays in the cytosolic compartment. Ser phosphorylations of $\mathrm{CPLA}_{2}$ and 5-LOX are indicated. GGT, $\gamma$ glutamyltransferase; MBD, membrane-bound dipeptidase.

5-LOX is also subjected to posttranslational modification. Thus, the enzyme is phosphorylated in vitro at three sites: Ser271 by MAPKAP kinase 2, Ser663 by ERK2, and Ser523 by PKA (23-25). Phosphorylation at Ser271 and Ser663 is facilitated by the presence of unsaturated fatty acids, including AA, but seems to influence enzyme activity indirectly via 5-LOX compartmentalization $(26,27)$. On the other hand, phosphorylation at Ser523 by PKA directly suppresses 5-LOX activity and its trafficking to the nucleus $(25,28)$, which may explain the inhibitory actions of adenosine and increased cAMP on cellular leukotriene synthesis (29). Interestingly, neutrophils and monocytes from males seem to have a significantly lower capacity to synthesize leukotrienes $(30,31)$. This effect is due to androgen-induced ERK activation, which paradoxically results in reduced leukotriene synthesis.

The 5-LOX protein and crystal structure. Human $5-\mathrm{LOX}$ is a $78-\mathrm{kDa}$ soluble enzyme that is generally regarded as monomeric, although recent data suggest that it can also exist as a homodimer (32). The enzyme is notoriously unstable and sensitive to oxidative damage, which made its initial purification from isolated human leukocytes a formidable challenge, finally overcome by Rouzer

Regulation of 5-LOX expression. The human 5-LOX gene is located on chromosome 10 and consists of 14 exons (15). The promoter region lacks a typical TATA or CCAT box but contains eight GC boxes, five of which are arranged in tandem and bind the transcription factors SP1 and EGR-1 $(16,17)$. Several natural mutations occur within the functional promoter regions, which have been suggested to play a role in asthma $(17,18)$. TGF- $\beta$ and vitamin $\mathrm{D}_{3}$ strongly increase 5-LOX expression and enzyme activity during differentiation of HL-60 and MonoMac6 human myeloid cells (19). In addition, granulocyte-macrophage CSF (GM-CSF) augments 5-LOX expression in mature human neutrophils, monocytes, and monocytic THP-1 cells (19). 5-LOX expression is also regulated by miR-19a-3p and miR-125b-5p in a cell type- and stimulus-specific manner (20).

A multicomponent system regulates 5-LOX enzyme activity. 5 -LOX is a non-heme dioxygenase whose activity is regulated by several soluble and membrane-associated factors acting as allosteric regulators or enzyme scaffolds. Thus, $\mathrm{Ca}^{2+}$, ATP, phosphatidylcholine (PC), cell membrane and diacylglycerols, lipid hydroperoxides, and CLP have all been shown to impact the turnover of the substrate (6).

The functional role of $\mathrm{Ca}^{2+}$ is not fully understood but requires the presence of PC or CLP, a $16-\mathrm{kDa}$ F-actin-binding protein that promotes the $\mathrm{LTA}_{4}$ synthase activity of 5-LOX (21). 5-LOX is also stimulated by ATP, which binds to the protein without any apparent hydrolysis of phosphodiester bonds, apparently acting as an allosteric activator (22). and Samuelsson in 1985 (33). For the same reasons, it took another 25 years until an engineered, stable variant of 5-LOX could be successfully crystallized and structurally characterized at $2.4 \AA$ resolution (34). 5-LOX consists of an N-terminal $\beta$-sandwich and an ironcontaining C-terminal catalytic domain (Figure 2). The N-terminal domain is composed of two 4 -stranded antiparallel $\beta$-sheets and is one of the defining members of the PLAT (polycystin-1, lipoxygenase, $\alpha$-toxin) domain family (35). The 5-LOX N-terminal domain has been shown to bind several regulatory factors, such as $\mathrm{Ca}^{2+}$, PC, and CLP, suggesting that this domain facilitates 5-LOX's association with membranes during catalysis (6). The catalytic domain is composed of several $\alpha$-helices, and iron is coordinated by three conserved His residues $(367,372,550)$ and the carboxylate moiety of the C-terminal Ile673. Unexpectedly, the structure of stable 5-LOX revealed a fully encapsulated catalytic machinery, i.e., the side chains of two aromatic amino acids at the active center (Phe177 and Tyr181) form a cork (termed "FY cork") that seals off the active site and closes the cavity for substrate entry (34). Further studies suggest that the "corking" amino acid Phe177 plays an important role for a fully functional active site, and His600 appears to be required to position the substrate for catalysis (36). Apparently, the concealed FY cork also plays a role in 5-LOX association with the nuclear membrane and its scaffold protein FLAP (37).

\section{FLAP, a critical 5-LOX accessory protein}

In activated immune cells, 5-LOX translocates to the ER and perinuclear membranes in response to $\mathrm{Ca}^{2+}$, a process accompa- 


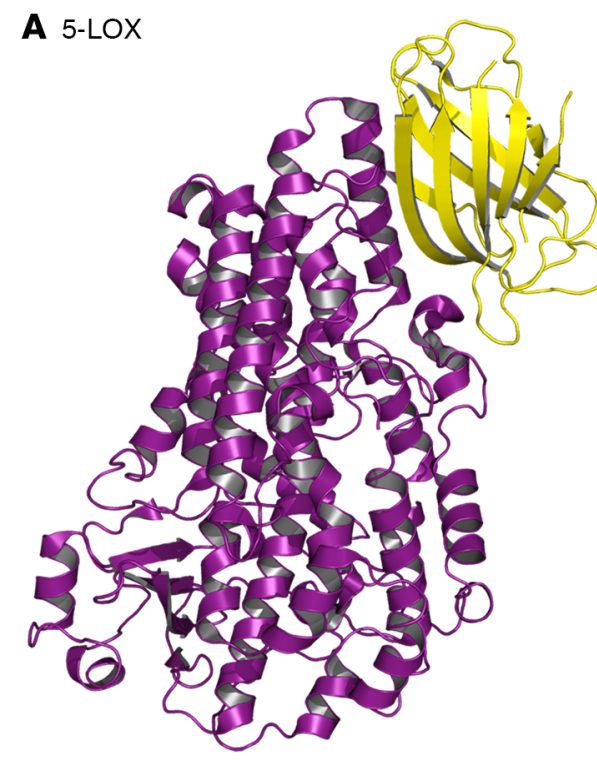

B FLAP
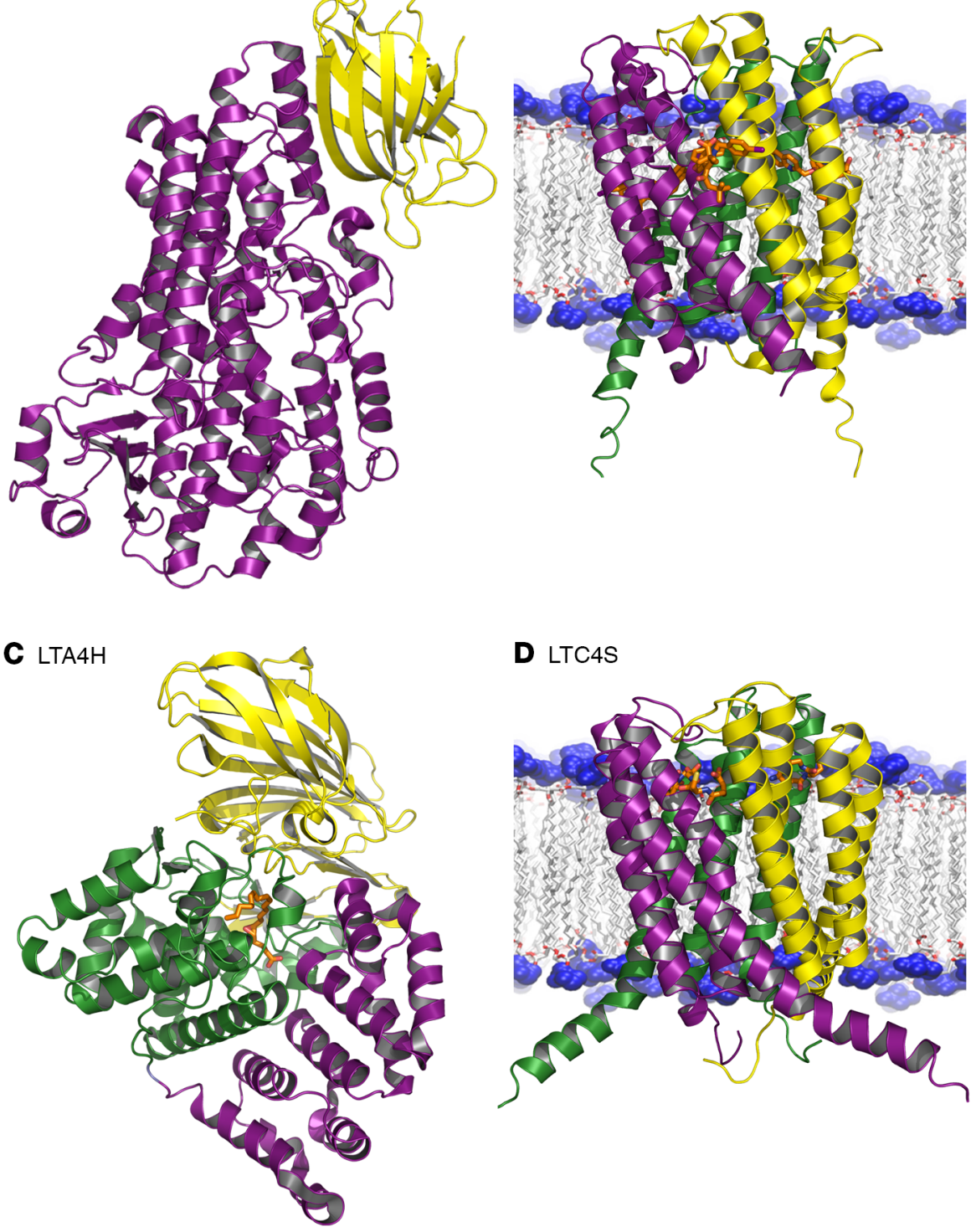

D LTC4S

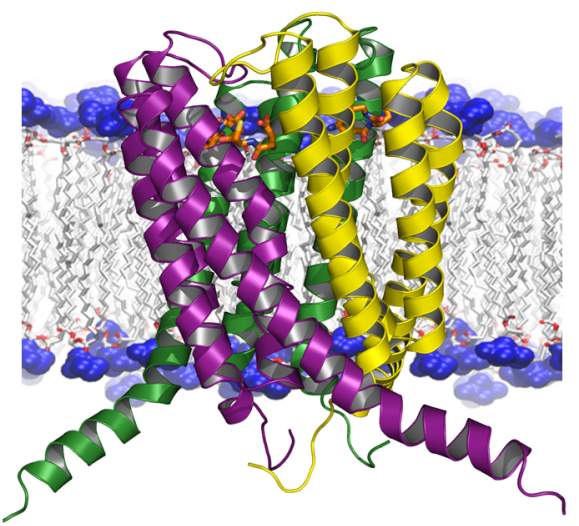

Figure 2. Crystal structure of the key enzymes and proteins in leukotriene biosynthesis. (A) Structure of 5-LOX at $2.4 \AA$ resolution depicting the $\mathrm{N}$-terminal $\beta$-barrel domain (yellow) and the catalytic domain (magenta). (B) Structure of FLAP at 4 A resolution. It is a trimer with each monomer (yellow, green, and magenta) composed of four transmembrane $\alpha$-helices. FLAP inhibitors are bound in the intermonomeric cleft. (C) Structure of LTA4H at 1.9 Å resolution. The protein is folded into three domains, an $\mathrm{N}$-terminal (yellow), a catalytic (green), and a C-terminal (magenta), between which the catalytic center is located. A molecule of LTA $_{4}$ is indicated in the center of the interdomain cavity. (D) Structure of LTC4S. It is a trimer with each monomer (yellow, green, and magenta) composed of 4 transmembrane $\alpha$-helices. Three molecules of the cosubstrate GSH are bound between two monomers toward the cytosolic side of the protein. Figures were derived from the following Protein Data Bank IDs: 5-LOX 308Y; FLAP 2Q7R; LTA4H 5NI6; LTC4S 2UUH. nied by enzyme catalysis followed by enzyme inactivation. At the membrane, 5-LOX associates with FLAP, which was originally discovered through the inhibitory action of a drug, MK-886, on leukotriene biosynthesis in intact cells $(38,39)$. MK-886 binds to FLAP, interferes with 5-LOX/FLAP interactions, and inhibits 5-LOX activity.

Role of FLAP in cellular leukotriene biosynthesis. Association between FLAP and 5-LOX has been demonstrated in vitro and in whole cells (40-43), involving four cysteines (159, 300, 416, and 418) in 5-LOX (42). The role of FLAP is to present AA to 5 -LOX $(39,44)$, and it is assumed that FLAP acts as a scaffold that governs the distribution of 5-LOX to the perinuclear region, stimulates AA utilization by 5-LOX, and increases the efficiency with which 5-LOX converts 5-HpETE into $\operatorname{LTA}_{4}(45,46)$. A recent study indicates that FLAP regulates 5 -LOX activity in two ways: by inducing an initial flexible and loose association with 5-LOX for efficient 5-LOX product synthesis, and by subsequent formation of a tight 5-LOX/FLAP complex that terminates 5-LOX activity (43).
Regulation of FLAP expression. The FLAP gene is located on chromosome 13 and comprises five exons (47). The promoter contains a possible TATA box, AP-2, NF- $\kappa$ B, and glucocorticoid response elements. The $5^{\prime}$-UTR region contains a polymorphism that is associated with asthma (48). Transcription of FLAP appears to be induced in inflammatory cells by IL-3 as well as GM-CSF, dexamethasone, IL-5, LPS, and TNF- $\alpha$ (49). Another study showed that hypoxia induces FLAP expression in endothelial cells via enhancement of HIF- $1 \alpha$ and NF- $\mathrm{BB}$ binding to the FLAP promoter, while expression is downregulated by miR-135a and miR-199a-5p targeting the 3'-UTR of FLAP mRNA (50).

FLAP protein and structure. Human FLAP is a 161-amino acid integral membrane protein (51). Notably, FLAP displays no enzyme activity (39). A low-resolution (4 A) structure of FLAP in complex with inhibitors revealed a trimeric structure with four transmembrane helices in each monomer connected by two cytosolic loops and one lumenal loop (52). The inhibitors bind to membraneembedded pockets in FLAP, suggesting how they might prevent binding of AA (Figure 2). 


\section{LTA4H, an epoxide hydrolase dedicated to $\mathrm{LTB}_{4}$ synthesis}

LTA4H catalyzes the final critical step in the biosynthesis of the proinflammatory compound $\mathrm{LTB}_{4}$, recently identified as a key signal-relay molecule during neutrophil chemotaxis and swarming $(53,54)$. Unlike other epoxide hydrolases, LTA4H is highly selective for its substrate, $\mathrm{LTA}_{4}$, and undergoes suicide inactivation during catalysis with covalent binding of LTA to the protein (55). It is presently unclear how $\mathrm{LTA}_{4}$, a labile and chemically reactive allylic epoxide, is transferred between 5-LOX and LTA4H and how the product $\mathrm{LTB}_{4}$ is transported through cytosol to the plasma membrane for export (Figure 1).

LTA $4 H$ is ubiquitously expressed. Unlike 5-LOX, LTA4H is widely expressed in almost all mammalian cells, organs, and tissues, albeit at different levels (56). Human LTA4H exists as a single copy on chromosome 12q22 divided into 19 exons (57). LTA4H expression is believed to be stable, although it has been reported that IL-4 and IL-13 may upregulate its expression in human PMNs (56). High levels of LTA4H have been observed in several human tumors of the gastrointestinal tract, lung, and thyroid, suggesting a role in cancer (58).

LTA $4 \mathrm{H}$ is a bifunctional zinc aminopeptidase. LTA4H is a $69-\mathrm{kDa}$ cytosolic protein that converts $\mathrm{LTA}_{4}$ into $\mathrm{LTB}_{4}$, a reaction referred to as the enzyme's epoxide hydrolase activity (Figure 1). LTA4H is also a tripeptidase with high affinity for N-terminal arginine (55, 59). Both enzyme activities of LTA4H depend on a catalytic zinc ion that is bound within the signature $\operatorname{HEXXH}-(\mathrm{X})_{18}-\mathrm{E}$, typical of M1 metallopeptidases (60). LTA4H's crystal structure has been determined (61). The enzyme folds into an $\mathrm{N}$-terminal domain, a catalytic domain, and a C-terminal domain (Figure 2). The interface of the domains forms an active site cavity, which narrows at the zinc-binding site, forming a tunnel into the catalytic domain. The opening and wider parts of the cavity are highly polar; the tunnel is more hydrophobic. LTA4H's two enzyme activities are exerted via distinct yet overlapping active sites. Thus, Glu296 and Tyr383 are specifically required for the aminopeptidase activity, whereas Asp375 is critical only for the epoxide hydrolase reaction. Glu271, Arg563, and the zinc ion are necessary for both catalyses. Interestingly, LTA4H utilizes a single water molecule that is differentially activated by Glu296 or Glu271 to take part in the aminopeptidase or epoxide hydrolase reaction, respectively (62).

LTA4H cleaves and inactivates the chemotactic Pro-Gly-Pro. Snelgrove and coworkers serendipitously discovered that the tripeptide Pro-Gly-Pro (PGP) is an endogenous substrate for extracellular LTA4H (63). PGP is generated from the extracellular matrix and is chemotactic for neutrophils, suggesting that LTA4H exhibits dual and opposite functions during an inflammatory response. In the initial phase, the enzyme's epoxide hydrolase activity will generate proinflammatory $\mathrm{LTB}_{4}$, while the aminopeptidase activity will inactivate the chemotactic PGP during the resolution phase. Notably, conflicting results regarding the properties of PGP were recently reported (64).

\section{LTC4S, a specialized CSH transferase producing asthma mediators}

Slow-reacting substance of anaphylaxis (SRS-A) is a classical mediator of asthma. Work awarded the Nobel Prize chemically characterized SRS-A and identified it as a mixture of $\mathrm{LTC}_{4}, \mathrm{LTD}_{4}$, and $\mathrm{LTE}_{4}$, i.e., the cys-LTs (65). LTC4S is a specialized membrane GSH $S$-transferase, which catalyzes conjugation of LTA 4 with GSH (Figure 1). High levels of enzyme expression and capacity to synthesize LTC $_{4}$ are observed in immune cells such as eosinophils, mast cells, and monocytes (66). Platelets also contain LTC4S, although these corpuscles cannot produce the substrate LTA $(67)$.

LTC4S is a notoriously unstable $18-\mathrm{kDa}$ enzyme that is stimulated by divalent cations and PC and stabilized by GSH. The primary structure contains consensus sequences for PKC phosphorylation, which reduces LTC4S activity (68). Recently, the ribosomal protein 56 kinase (p70S6K) was shown to play a key role in phosphoregulation of LTC4S in human macrophages, and Ser36 was identified as the major phosphorylation site $(69,70)$.

LTC4S is a member of the MAPEG superfamily. Molecular cloning of LTC 4 S revealed a surprising 33\% identity with FLAP (71, 72), and further work at Merck Frosst identified two additional homologous microsomal GSH transferases: MGST2 and MGST3 $(73,74)$. MGST2 is $44 \%$ identical with LTC4S and accounts for LTC $_{4}$ synthesis in nonhematopoietic cells such as endothelium and testis (75-77). Recently, MGST2 was identified as a key enzyme involved in oxidative DNA damage induced by ER stress and anticancer agents (78). Yet another homolog was subsequently found to catalyze isomerization of prostaglandin $\mathrm{H}_{2}\left(\mathrm{PGH}_{2}\right)$ into prostaglandin $\mathrm{E}_{2}\left(\mathrm{PGE}_{2}\right)$ and was denoted microsomal prostaglandin E synthase type 1 (mPGES-1). This enzyme is induced by LPS and cytokines in tandem with COX-2 and appears to be the origin of $\mathrm{PGE}_{2}$ synthesized during inflammation (79-81). LTC4S, FLAP, MGST1, MGST2, MGST3, and mPGES-1 are now recognized as members of a common superfamily of integral membrane proteins denoted MAPEG (membrane-associated proteins in eicosanoid and glutathione metabolism) (82). The human LTC4S gene is located on chromosome $5 \mathrm{q} 35$ and has a structure similar to that of the FLAP gene (83). Promoter characterization has shown that an SP1 site and a putative initiator element (Inr) are involved in noncell-specific expression, whereas a Krüppel-like transcription factor and SP1 are implied in cell-specific regulation of LTC4S (84). LTC4S expression is induced by cytokines and phorbol-12myristate-13-acetate (PMA) in human erythroleukemia cells as well as in human eosinophils developed from IL-3- and IL-5treated cord blood progenitors $(67,85)$. The enzyme is also upregulated in the monocytic cell line THP- 1 after TGF- $\beta$ treatment, apparently via SP1 and SP3 $(86,87)$. In addition, IL-4 strongly induces expression of LTC4S in cord blood-derived human mast cells and bone marrow-derived mouse mast cells, a response that may be signaled via STAT-6 (88). Finally, intraperitoneal injection of LPS in the rat caused in vivo induction of the enzyme in liver, heart, adrenal gland, and brain (89).

Crystal structure of LTC4S. The crystal structure of human LTC4S has been solved at high resolution $(90,91)$. The enzyme is a trimer, and each monomer is composed of $5 \alpha$-helices, four of which traverse the membrane (Figure 2). The lipid (LTA $)$ ) binding site is believed to be located in a hydrophobic crevice formed at the interface between two adjacent monomers. The GSH bound deeper in the protein below the hydrophobic cleft adopts a peculiar horseshoe-shaped conformation. Residues from two monomers are involved in GSH binding, and mutagenetic analysis 
has demonstrated that Arg104 is catalytic and rapidly activates the GSH thiol $(92,93)$.

\section{Leukotriene biosynthetic complexes at $E R$ and perinuclear membranes}

The superordinate enzymes in leukotriene biosynthesis, cPLA2 $\alpha$ (which provides AA) and 5-LOX (which converts AA into LTA 4 ), traffic from cytosol to the ER and perinuclear membranes in response to cell activation (Figure 1). In the target compartment, FLAP and LTC4S are embedded in the membrane, ready to support biosynthesis of $\mathrm{LTA}_{4}$ and its further conversion into $\mathrm{LTC}_{4}(94$, 95). In fact, biophysical evidence indicates that FLAP and LTC4S form functional heterodimers and trimers within the membrane and that FLAP can act as a scaffold protein for association of 5 -LOX, thus creating a multiprotein biosynthetic complex on both the outer and inner nuclear membranes $(40,96)$. It is not clear how AA, liberated by cPLA $2 \alpha$, can first reach its binding site in FLAP, travel further to the active site of 5-LOX, and, after conversion into $\mathrm{LTA}_{4}$, reach the terminal LTA4H and LTC4S. To synchronize this machinery, it seems necessary that both cPLA2 $\alpha$ and 5-LOX are juxtaposed in direct contact with the nuclear membrane and that all biosynthetic components are spatially interconnected. Since LTA4H is soluble and does not translocate to the nuclear membrane, transfer of LTA $_{4}$ from 5-LOX to LTA4H seems to require a carrier, and recent data indicate that this process involves substantial conformational changes within LTA4H, accompanied by gated entry of $\operatorname{LTA}_{4}(62)$.

\section{Therapeutic and pharmacological opportunities and pitfalls}

It is not within the scope of this Review to give a comprehensive description of all pathologies potentially involving leukotrienes. Here, I would like to mention four disease areas that are currently attracting considerable attention. Firstly, leukotrienes are strongly implicated in immunometabolic disorders ranging from obesity to type 2 diabetes. It has been demonstrated that enzymes and receptors of the 5-LOX pathway are upregulated in adipose tissue and that mouse and human adipocytes can secrete leukotrienes (97, 98). Importantly, $\mathrm{LTB}_{4}$ appears to play a critical role in adipose tissue inflammation, and a FLAP antagonist reduced 5-LOX products and macrophage accumulation in adipose tissue in mice with dietary obesity (97). In addition, pharmacological or genetic ablation of the 5-LOX pathway in WT mice on a high-fat diet resulted in a reduction of adipose tissue macrophage and insulin resistance (98). Recent data demonstrate a similar role for $\mathrm{LTB}_{4}$ in promoting liver steatosis and insulin resistance in muscle and adipose tissue, reinforcing the role of the $\mathrm{LTB}_{4} /$ BLT1 signaling axis as a main driver for the inflammation-insulin resistance syndrome in obesity (99). Similar work on the BLT1 receptor corroborates the notion that inhibition of $\mathrm{LTB}_{4}$ signaling can be a useful therapeutic strategy in diseases related to insulin resistance (100).

An increasing body of evidence also suggests that 5-LOX and leukotrienes are involved in neurodegenerative disorders such as Alzheimer's disease (AD). The 5-LOX pathway seems to modulate AD pathology at multiple levels (101). Using transgenic mouse models of $\mathrm{AD}$, it was demonstrated that 5-LOX deficiency decreases amyloid $\beta$ peptides, which translates to fewer amyloid $\beta$ plaques and reduced total amyloid burden in the brain, apparently through elevation of all components of the $\gamma$-secretase complex (102). Furthermore, 5-LOX contributes to tau hyperphosphorylation, compromised synaptic function, and memory deficits. Notably, pharmacological or genetic inhibition of 5-LOX counteracts all these effects and can even restore learning and memory impairments (103-107). A recent study suggests that cys-LTs may play a role in $\mathrm{AD}$, as a selective CysLT1 antagonist reduced neuroinflammation, elevated hippocampal neurogenesis, and improved learning and memory in rats (108).

Leukotrienes have long been linked to cardiovascular diseases, and major efforts have been invested into development of antileukotrienes for prevention of atherosclerosis and treatment of myocardial infarction $(49,109,110)$. Here, I would like to highlight two other pathologies of the cardiovascular system, namely, pulmonary hypertension (PH) and abdominal aortic aneurysm (AAA), both of which appear to be associated with leukotrienes and thus possibly amenable to antileukotriene treatments targeting the enzyme machinery.

Early work in rats and mice linked the 5-LOX pathway to hypoxia-induced $\mathrm{PH}$, and 5-LOX expression was increased in pulmonary macrophages and pulmonary artery endothelial cells in patients with idiopathic pulmonary arterial hypertension (111, 112). These findings were specious, because a prominent pathological feature of $\mathrm{PH}$ is accumulation of macrophages near the arterioles of the lung. Further investigations pointed to a critical role of $\mathrm{LTB}_{4}$ in the disease process. Thus, studies in several rat models of $\mathrm{PH}$ as well as cells and tissue samples from patients with $\mathrm{PH}$ revealed elevated levels of $\mathrm{LTB}_{4}$, both systemically and locally in lung tissue, and high levels of LTA4H were observed in accumulated macrophages (113-115). At a functional level, macrophage-derived $\mathrm{LTB}_{4}$ was shown to induce apoptosis of pulmonary artery endothelial cells as well as proliferation and hypertrophy of pulmonary smooth muscle cells (113). Furthermore, $\mathrm{LTB}_{4}$ can activate pulmonary artery fibroblasts (116).

Leukotrienes are also involved in AAA disease. In early work on mouse models of atherosclerosis, 5-LOX deficiency protected against AAA, results that could not be reproduced in the angiotensin II-induced model of AAA $(117,118)$. Based on work with human tissue samples, it was proposed that $\mathrm{LTB}_{4}$ plays a role in AAA as a chemotactic factor released from neutrophils within the intraluminal thrombus; cys-LTs were identified as main 5-LOX products in human AAA wall and could be linked to release of matrix metalloproteinases $(119,120)$. In agreement with these data, inhibition of 5-LOX by pharmacological or genetic approaches attenuated aneurysm formation in two different AAA mouse models (121). Only very recently, we showed that cys-LTs are involved in AAA and that the common asthma drug montelukast, a selective CysLT1 antagonist, afforded protection in three different mouse models of AAA (122). The therapeutic significance of this study lies in the fact that montelukast is a well-tolerated and safe drug that can be directly tested in a human clinical trial. However, it is possible that an inhibitor of LTC4S, alone or in combination with an inhibitor of LTA4H, could prove more effective (see below).

5-LOX and FLAP bridge proinflammatory and pro-resolving pathways. 5-LOX inhibitors are divided into three classes depending on their mode of action: (a) redox inhibitors, (b) iron-binding inhibitors, and (c) active site-directed inhibitors. The early com- 


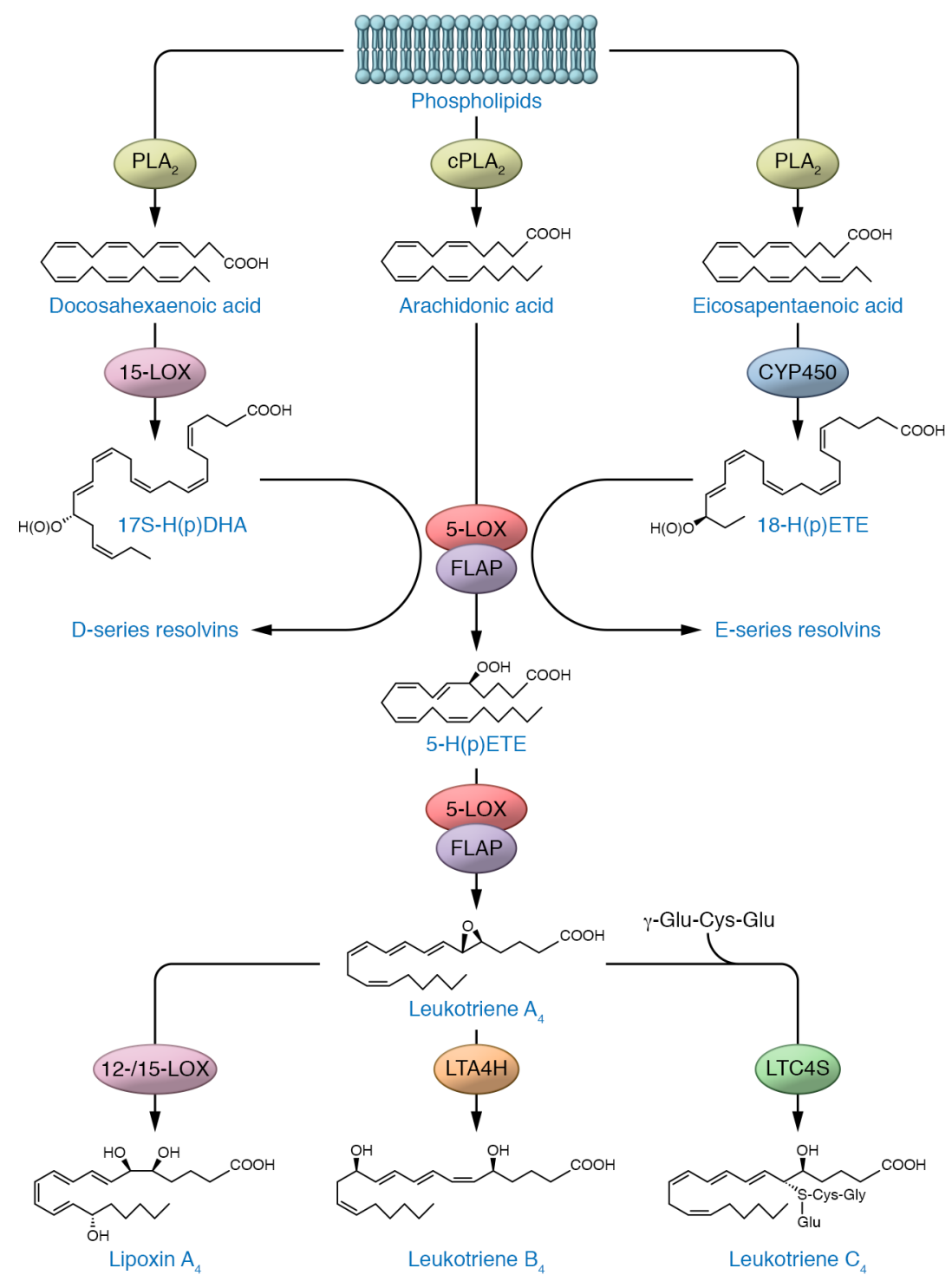

Figure 3. Metabolism of polyunsaturated fatty acids into leukotrienes and resolvins. The scheme illustrates the interconnections between the pathways for synthesis of proinflammatory leukotrienes and antiinflammatory lipoxins and resolvins from arachidonic, eicosapentaenoic, and docosahexaenoic acids. For D- and E-series resolvins, the respective fatty acid substrate is first oxygenated by 15 -LOX or cytochrome P450. Inhibition of 5-LOX attenuates leukotriene formation and may interfere with synthesis of pro-resolving molecules. Inhibition of LTA4H and/or LTC4S will block leukotrienes, shunt LTA $_{4}$ into lipoxin synthesis, and spare 5-LOX activity for generation of other pro-resolving molecules. pounds suffered from lack of selectivity, structure-activity relationships, and enantioselectivity; moreover, they elevated methemoglobin levels and displayed poor efficiency and oral availability (1). Nonetheless, in clinical trials, zileuton showed beneficial effects in many inflammatory diseases, and today zileuton is marketed in the United States for treatment of asthma. With the crystal structure of 5-LOX at hand, structure-based approaches have become possible, although a complex between enzyme and an inhibitor has not yet been presented. Nonetheless, a stream of new 5-LOX inhibitors, either synthesized or naturally occurring, have been presented in recent years, but their clinical utility has not been tested $(123,124)$.

Several inhibitors of FLAP have also been developed over the years: the classical prototype MK-886, the follow-up MK-0591, and Bay-X1005 (1). A second generation of FLAP inhibitors was also developed from the lead molecule denoted AM103, primarily intended for use as an anti-asthma medication $(125,126)$. Crystal structures of FLAP in complex with inhibitors have been reported (52), but the resolution was rather low, limiting its use in structurebased approaches to drug design (Figure 2).
5-LOX converts AA into $\mathrm{LTA}_{4}$, which can be lipoxygenated into lipoxin $\mathrm{A}_{4}\left(\mathrm{LXA}_{4}\right)$ and also appears to be involved in the biosynthesis of pro-resolving molecules originating from eicosapentaenoic and docosahexaenoic acids (Figure 3 and ref. 127). This dual role of 5-LOX at the crossroads of both proinflammatory leukotrienes and pro-resolving mediators may weaken the prospects of developing antiphlogistic drugs targeting 5-LOX. However, the roles of 5-LOX and FLAP in biosynthesis of pro-resolving mediators are complex. In one study, lipoxin and resolvin biosynthesis was shown to depend on the presence of FLAP, suggesting that a selective FLAP inhibitor will not allow continued 5-LOX activity for production of pro-resolving mediators (128), while another recent study showed that FLAP inhibition does not affect synthesis of pro-resolving mediators from endogenous docosahexaenoic acid (129). Moreover, it appears that cytosolic 5-LOX, uncoupled to FLAP, favors synthesis of pro-resolving mediators over $\mathrm{LTB}_{4}$ (130). Interestingly, FLAP and certain 5-LOX inhibitors are more effective in females, and apparently these sex differences are caused by androgens impeding assembly of the leukotrienebiosynthetic 5-LOX/FLAP complex (131). 
LTA4H, target for development of resolution-promoting molecules. Development of inhibitors targeting LTA4H began when its zinc content and aminopeptidase activity were discovered, offering a simple model of the active site (55). Thus, academicians identified bestatin and captopril as LTA4H inhibitors (132), which were followed by various transition state mimics $(133,134)$. Searle/ Pharmacia developed the clinical candidate SC-57461A, which is today's benchmark for a potent and selective inhibitor (135). With the crystal structure of LTA4H, programs on rational inhibitor design began within industry. Thus, deCode Genetics developed DG-51 for treatment of myocardial infarction and stroke, while Johnson \& Johnson developed JNJ-26993135 for treatment of inflammatory bowel disease and allergic airway inflammation (136-139). Similarly, work at Berlex/Schering led to the development of acebilustat, which is currently in clinical trial for treatment of cystic fibrosis (140). Two additional LTA4H inhibitors, bestatin and tosedostat, are presently entering clinical trials (141). Bestatin is intended for use in pulmonary arterial hypertension and lymphoedema, while tosedostat is an antineoplastic agent for treatment of a variety of severe cancers. However, both bestatin and tosedostat are general aminopeptidase inhibitors, and their pharmacological actions may well be off-target effects (141).

Inhibitors of LTA4H not only block $\mathrm{LTB}_{4}$ synthesis, they also spare 5-LOX-derived LTA 4 to allow shunting into lipoxin synthesis (Figure 3 and refs. 138, 139). In addition, we recently developed a new class of LTA4H inhibitors, typified by the lead molecule ARM1, that selectively block synthesis of LTB $_{4}$ while preserving the peptidolytic inactivation of chemotactic PGP (142). Hence, this type of inhibitor will inhibit LTB $_{4}$ synthesis, enhance lipoxin generation, and salvage PGP inactivation, offering a greater therapeutic potential as compared with previously developed small molecules.

LTC4S inhibitors are lukast alternatives with resolutionpromoting properties. In spite of its central role in allergic inflammation, very few specific inhibitors of LTC4S have been developed thus far (143-145). This may reflect the success of CysLT1 antagonists, collectively referred to as "lukasts," that are currently used in clinical management of asthma. However, a new generation of lukasts is needed, because a significant proportion of asthma patients $(\sim 40 \%)$ do not respond to these drugs. In addition, new receptors for cys-LTs have been discovered that are functionally interconnected and cross-regulated (146-149). Hence, the upstream biosynthetic enzyme LTC4S may well prove to be an effective target for pharmacological inhibition of cys-LT signaling, not only for asthma but also for other diseases involving cys-LTs such as AAA, celiac disease, and neurodegenerative disorders $(108,122,150)$. It is clear that inhibitors of LTC4S can be made selective among other MAPEG enzymes and effective in vivo, and permit shunting of LTA $_{4}$ into LXA 4 synthesis (145).

Antileukotrienes target a metabolic system with multiple levels of complexity. According to the current dogma, leukotrienes are formed within a time frame of seconds to a few minutes following an acute cell stimulus, causing calcium mobilization and activation of 5-LOX. However, synthesis of leukotrienes can occur in response to cell stress without calcium mobilization, and in some instances biosynthesis can proceed over longer periods of time, even hours, in a cell type- and stimulus-dependent manner (27, $129,151)$. Moreover, resting monocytes cultured with GM-CSF produce significant amounts of $\mathrm{LXA}_{4}$, which normally involves 5-LOX activity, without concomitant synthesis of appreciable quantities of leukotrienes (152). Apparently, the activity of 5-LOX and downstream enzymes depends on a multitude of factors leading to differential profiles of mediators in any given cellular context.

It is also important to keep in mind that enzymes of leukotriene biosynthesis interact with other proteins and/or possess secondary catalytic activities, adding additional levels of complexity to the biosynthetic machinery. For instance, 5 -LOX is present in the nucleus and interacts with Dicer, suggesting that it may exert effects on micro-RNAs and regulation of other genes (153). 5-LOX also interacts with cytosolic CLP, the functional consequences of which are only beginning to be described (46). Furthermore, LTA4H carries an aminopeptidase activity, and although PGP has been identified as one endogenous substrate, there are probably other substrates and more to learn about this enzyme activity. Similarly, most MAPEG members possess a peroxidase activity toward lipid hydroperoxides and may thus help control the redox milieu at the nuclear membrane with potential consequences for a variety of cellular processes. Hence, caution is warranted in evaluating the effects of pharmacological intervention within the leukotriene cascade, since enzyme inhibitors may give rise to unanticipated effects that may, or may not, be related to attenuated leukotriene synthesis.

\section{Concluding remarks}

The powerful bioactivities of leukotrienes have motivated academia and the pharmaceutical industry to develop antileukotriene drugs to treat a range of inflammatory diseases $(1,124)$. To date, CysLT1 antagonists and one 5-LOX inhibitor have reached the clinic and are used for medical treatment of asthma and allergic rhinitis. The pharmaceutical industry prefers to develop drugs as a single molecule against a single target. However, this classical type of approach has not provided satisfying results when targeting the leukotriene cascade, which may have several explanations. Thus, results from preclinical research on leukotrienes may sometimes poorly reflect the human pathology, and therefore its predictive value for successful drug development may be limited. In addition, leukotrienes are generated by activated leukocytes, and the impact of these mediators will depend on temporal accumulation and composition of immune cells at various stages of the disease process.

Most likely, disappointing outcomes also originate from the fact that branches of the metabolic pathways are interconnected in a complex manner, and a targeted blockade may cause shunting of metabolites to other families of lipid mediators with opposing bioactions, mitigating the effects of the primary intervention.

With increasing knowledge about the flux of metabolites, new "smart" combinations of drugs can be designed. For instance, rather than blocking 5-LOX to eliminate all leukotrienes, one could combine inhibitors of the downstream LTA4H and LTC4S to shunt LTA into lipoxins and to preserve 5-LOX-dependent biosynthesis of other pro-resolving mediators (Figure 3). The spectrum of opportunities increases even further if receptor antagonists and inhibitors of the COX cascade are taken into consideration. Since there is a significant interindividual variation in leukotriene and lipid mediator biosynthesis, it may be necessary and possible in the future to assess lipid 
profiles in individual patients to guide tailor-made personalized drug combinations to achieve effective clinical results. We are now experiencing the uncovering of new leukotriene-dependent pathologies, and as the details of the mechanisms regulating the biosynthetic pathways become better understood and controlled, opportunities for development of new drugs, as well as repurposing of already existing drugs, are clearly emerging.

\section{Acknowledgments}

The author is grateful to Xiao Tang and Madhuranayaki Thulasingam for preparation of figures. Work in the author's labora- tory was supported by grant 10350 from the Swedish Research Council; Linnaeus Center of Excellence for Research on Inflammation and Cardiovascular Disease (CERIC) grant 70870302; the Novo Nordisk Foundation (NNF15CC0018346 and NNF15CC0018486); and a Distinguished Professor Award from Karolinska Institutet.

Address correspondence to: Jesper Z. Haeggström, Department of Medical Biochemistry and Biophysics, Division of Chemistry 2, Karolinska Institutet, S-171 77 Stockholm, Sweden. Phone: 46.8.52487612; Email: jesper.haeggstrom@ki.se.
1. Haeggström JZ, Funk CD. Lipoxygenase and leukotriene pathways: biochemistry, biology, and roles in disease. Chem Rev. 2011;111(10):5866-5898.

2. Nakamura M, Shimizu T. Leukotriene receptors. Chem Rev. 2011;111(10):6231-6298.

3. Peters-Golden M, Henderson WR Jr. Leukotrienes. N Engl J Med. 2007;357(18):1841-1854.

4. Araújo AC, Wheelock CE, Haeggström JZ. The eicosanoids, redox-regulated lipid mediators in immunometabolic disorders [published online ahead of print December 11, 2017]. Antioxid Redox Signal.https://doi.org/10.1089/ ars.2017.7332.

5. Leslie CC. Cytosolic phospholipase $\mathrm{A}_{2}$ : physiological function and role in disease. J Lipid Res. 2015;56(8):1386-1402.

6. Rådmark O, Werz O, Steinhilber D, Samuelsson B. 5-Lipoxygenase, a key enzyme for leukotriene biosynthesis in health and disease. Biochim Biophys Acta. 2015;1851(4):331-339.

7. Rouzer CA, Matsumoto T, Samuelsson B. Single protein from human leukocytes possesses 5-lipoxygenase and leukotriene A4 synthase activities. Proc Natl Acad Sci U S A. 1986;83(4):857-861.

8. Peters-Golden M, Brock TG. Intracellular compartmentalization of leukotriene synthesis: unexpected nuclear secrets. FEBS Lett. 2001;487(3):323-326.

9. Luo M, Jones SM, Peters-Golden M, Brock TG. Nuclear localization of 5-lipoxygenase as a determinant of leukotriene B4 synthetic capacity. Proc Natl Acad Sci U S A. 2003;100(21):12165-12170.

10. Gupta S, Srivastava M, Ahmad N, Sakamoto K, Bostwick DG, Mukhtar H. Lipoxygenase-5 is overexpressed in prostate adenocarcinoma. Cancer. 2001;91(4):737-743.

11. Ding X, Zhu C, Qiang H, Zhou X, Zhou G. Enhancing antitumor effects in pancreatic cancer cells by combined use of COX- 2 and 5-LOX inhibitors. Biomed Pharmacother. 2011;65(7):486-490.

12. Sveinbjörnsson B, et al. Expression of enzymes and receptors of the leukotriene pathway in human neuroblastoma promotes tumor survival and provides a target for therapy. FASEB $J$. 2008;22(10):3525-3536.

13. Wang D, Dubois RN. Eicosanoids and cancer. Nat Rev Cancer. 2010;10(3):181-193.

14. Qiu H, Strååt K, Rahbar A, Wan M, SöderbergNauclér C, Haeggström JZ. Human CMV infection induces 5-lipoxygenase expression and leukotriene B4 production in vascular smooth muscle cells. J Exp Med. 2008;205(1):19-24.
15. Funk CD, Hoshiko S, Matsumoto T, Rdmark O, Samuelsson B. Characterization of the human 5-lipoxygenase gene. Proc Natl Acad Sci U S A. 1989;86(8):2587-2591.

16. Hoshiko S, Rådmark O, Samuelsson B. Characterization of the human 5-lipoxygenase gene promoter. Proc Natl Acad Sci U S A. 1990;87(23):9073-9077.

17. Silverman ES, Drazen JM. Genetic variations in the 5-lipoxygenase core promoter. Description and functional implications. Am J Respir Crit Care Med. 2000;161(2 pt 2):S77-S80.

18. Kalayci O, et al. ALOX5 promoter genotype, asthma severity and LTC production by eosinophils. Allergy. 2006;61(1):97-103.

19. Steinhilber D, Rådmark O, Samuelsson B. Transforming growth factor beta upregulates 5 -lipoxygenase activity during myeloid cell maturation. Proc Natl Acad Sci U S A. 1993;90(13):5984-5988.

20. Busch S, et al. 5-lipoxygenase is a direct target of miR-19a-3p and miR-125b-5p. J Immunol. 2015;194(4):1646-1653.

21. Rakonjac M, et al. Coactosin-like protein supports 5-lipoxygenase enzyme activity and up-regulates leukotriene A4 production. Proc Natl Acad Sci U S A. 2006;103(35):13150-13155.

22. Smyrniotis CJ, Barbour SR, Xia Z, Hixon MS, Holman TR. ATP allosterically activates the human 5-lipoxygenase molecular mechanism of arachidonic acid and 5(S)-hydroperoxy-6(E), 8(Z),11(Z),14(Z)-eicosatetraenoic acid. Biochemistry. 2014;53(27):4407-4419.

23. Werz O, Klemm J, Samuelsson B, Rådmark O. 5-Lipoxygenase is phosphorylated by $\mathrm{p} 38$ kinasedependent MAPKAP kinases. Proc Natl Acad Sci US A. 2000;97(10):5261-5266.

24. Werz O, et al. Extracellular signal-regulated kinases phosphorylate 5-lipoxygenase and stimulate 5-lipoxygenase product formation in leukocytes. FASEB J. 2002;16(11):1441-1443.

25. Luo M, Jones SM, Phare SM, Coffey MJ, PetersGolden M, Brock TG. Protein kinase A inhibits leukotriene synthesis by phosphorylation of 5 -lipoxygenase on serine 523. J Biol Chem. 2004;279(40):41512-41520.

26. Werz O, Szellas D, Steinhilber D, Rådmark O. Arachidonic acid promotes phosphorylation of 5-lipoxygenase at Ser-271 by MAPKactivated protein kinase 2 (MK2). J Biol Chem. 2002;277(17):14793-14800.

27. Werz O, Bürkert E, Samuelsson B, Rådmark O, Steinhilber D. Activation of 5-lipoxygenase by cell stress is calcium independent in human polymorphonuclear leukocytes. Blood. 2002;99(3):1044-1052.

28. Luo M, Jones SM, Flamand N, Aronoff DM, PetersGolden M, Brock TG. Phosphorylation by protein kinase a inhibits nuclear import of 5-lipoxygenase. JBiol Chem. 2005;280(49):40609-40616.

29. Flamand N, Surette ME, Picard S, Bourgoin S, Borgeat P. Cyclic AMP-mediated inhibition of 5-lipoxygenase translocation and leukotriene biosynthesis in human neutrophils. Mol Pharmacol. 2002;62(2):250-256.

30. Pergola C, et al. ERK-mediated regulation of leukotriene biosynthesis by androgens: a molecular basis for gender differences in inflammation and asthma. Proc Natl Acad Sci U S A. 2008;105(50):19881-19886.

31. Pergola C, et al. Testosterone suppresses phospholipase $\mathrm{D}$, causing sex differences in leukotriene biosynthesis in human monocytes. FASEB J. 2011;25(10):3377-3387.

32. Häfner AK, et al. Dimerization of human 5-lipoxygenase. Biol Chem. 2011;392(12):1097-1111.

33. Rouzer CA, Samuelsson B. On the nature of the 5-lipoxygenase reaction in human leukocytes: enzyme purification and requirement for multiple stimulatory factors. Proc Natl Acad Sci U S A. 1985;82(18):6040-6044.

34. Gilbert NC, et al. The structure of human 5-lipoxygenase. Science. 2011;331(6014):217-219.

35. Allard JB, Brock TG. Structural organization of the regulatory domain of human 5-lipoxygenase. Curr Protein Pept Sci. 2005;6(2):125-131.

36. Mitra S, Bartlett SG, Newcomer ME. Identification of the substrate access portal of 5-lipoxygenase. Biochemistry. 2015;54(41):6333-6342.

37. Gerstmeier J, et al. 5-Lipoxygenase-activating protein rescues activity of 5-lipoxygenase mutations that delay nuclear membrane association and disrupt product formation. FASEB J 2016;30(5):1892-1900.

38. Rouzer CA, Ford-Hutchinson AW, Morton HE, Gillard JW. MK886, a potent and specific leukotriene biosynthesis inhibitor blocks and reverses the membrane association of 5-lipoxygenase in ionophore-challenged leukocytes. J Biol Chem. 1990;265(3):1436-1442.

39. Evans JF, Ferguson AD, Mosley RT, Hutchinson JH. What's all the FLAP about?: 5-lipoxygenaseactivating protein inhibitors for inflammatory diseases. Trends Pharmacol Sci. 2008;29(2):72-78.

40. Mandal AK, et al. The nuclear membrane organization of leukotriene synthesis. Proc Natl Acad Sci US A. 2008;105(51):20434-20439. 
41. Strid T, et al. Distinct parts of leukotriene C(4) synthase interact with 5-lipoxygenase and 5 -lipoxygenase activating protein. Biochem Biophys Res Commun. 2009;381(4):518-522.

42. Häfner AK, et al. Characterization of the interaction of human 5-lipoxygenase with its activating protein FLAP. Biochim Biophys Acta. 2015;1851(11):1465-1472.

43. Gerstmeier J, Weinigel C, Rummler S, Rådmark O, Werz O, Garscha U. Time-resolved in situ assembly of the leukotriene-synthetic 5-lipoxygenase/5-lipoxygenase-activating protein complex in blood leukocytes. FASEB J. 2016;30(1):276-285.

44. Mancini JA, et al. 5-Lipoxygenase-activating protein is an arachidonate binding protein. FEBS Lett. 1993;318(3):277-281.

45. Abramovitz M, Wong E, Cox ME, Richardson CD, Li C, Vickers PJ. 5-Lipoxygenase-activating protein stimulates the utilization of arachidonic acid by 5-lipoxygenase. Eur JBiochem. 1993;215(1):105-111.

46. Basavarajappa D, Wan M, Lukic A, Steinhilber D, Samuelsson B, Rådmark O. Roles of coactosin-like protein (CLP) and 5-lipoxygenase-activating protein (FLAP) in cellular leukotriene biosynthesis. Proc Natl Acad Sci U S A. 2014;111(31):11371-11376.

47. Kennedy BP, Diehl RE, Boie Y, Adam M, Dixon RA. Gene characterization and promoter analysis of the human 5-lipoxygenase-activating protein (FLAP). J Biol Chem. 1991;266(13):8511-8516.

48. Koshino T, et al. Novel polymorphism of the 5-lipoxygenase activating protein (FLAP) promoter gene associated with asthma. Mol Cell Biol Res Commun. 1999;2(1):32-35.

49. Wan M, Tang X, Stsiapanava A, Haeggstrom JZ. Biosynthesis of leukotriene $\mathrm{B}_{4}$. Semin Immunol. 2017;33:3-15.

50. Gonsalves CS, Kalra VK. Hypoxia-mediated expression of 5-lipoxygenase-activating protein involves HIF- $1 \alpha$ and NF- $\kappa$ B and microRNAs 135a and 199a-5p. J Immunol. 2010;184(7):3878-3888.

51. Dixon RA, et al. Requirement of a 5-lipoxygenaseactivating protein for leukotriene synthesis. Nature. 1990;343(6255):282-284.

52. Ferguson $\mathrm{AD}$, et al. Crystal structure of inhibitorbound human 5-lipoxygenase-activating protein. Science. 2007;317(5837):510-512.

53. Afonso PV, et al. LTB4 is a signal-relay molecule during neutrophil chemotaxis. Dev Cell. 2012;22(5):1079-1091.

54. Lämmermann T, et al. Neutrophil swarms require LTB4 and integrins at sites of cell death in vivo. Nature. 2013;498(7454):371-375.

55. Haeggström JZ. Leukotriene A4 hydrolase/aminopeptidase, the gatekeeper of chemotactic leukotriene B4 biosynthesis. J Biol Chem. 2004;279(49):50639-50642.

56. Zaitsu M, et al. New induction of leukotriene A(4) hydrolase by interleukin- 4 and interleukin- 13 in human polymorphonuclear leukocytes. Blood. 2000;96(2):601-609.

57. Mancini JA, Evans JF. Cloning and characterization of the human leukotriene A4 hydrolase gene. Eur J Biochem. 1995;231(1):65-71.

58. Chen X, Wang S, Wu N, Yang CS. Leukotriene A4 hydrolase as a target for cancer prevention and therapy. Curr Cancer Drug Targets. 2004;4(3):267-283.
59. Tholander F, Muroya A, Roques BP, FourniéZaluski MC, Thunnissen MM, Haeggström JZ. Structure-based dissection of the active site chemistry of leukotriene A4 hydrolase: implications for M1 aminopeptidases and inhibitor design. Chem Biol. 2008;15(9):920-929.

60. Barret AJ, Rawlings ND, Woessner JF. Family M1 of membrane alanyl aminopeptidase. In: Barret AJ, Rawlings ND, Woessner JF, eds. Handbook of Proteolytic Enzymes. San Diego, California, USA: Academic Press; 1998:994-996.

61. Thunnissen MM, Nordlund P, Haeggström JZ. Crystal structure of human leukotriene A(4) hydrolase, a bifunctional enzyme in inflammation. Nat Struct Biol. 2001;8(2):131-135.

62. Stsiapanava A, Samuelsson B, Haeggström JZ. Capturing LTA4 hydrolase in action: insights to the chemistry and dynamics of chemotactic LTB4 synthesis. Proc Natl Acad Sci U S A. 2017;114(36):9689-9694.

63. Snelgrove RJ, et al. A critical role for LTA4H in limiting chronic pulmonary neutrophilic inflammation. Science. 2010;330(6000):90-94.

64. Numao S, et al. Feasibility and physiological relevance of designing highly potent aminopeptidasesparing leukotriene A4 hydrolase inhibitors. Sci Rep. 2017;7(1):13591.

65. Samuelsson B. Leukotrienes: mediators of imme diate hypersensitivity reactions and inflammation. Science. 1983;220(4597):568-575.

66. Lam BK, Austen KF. Leukotriene C4 synthase: a pivotal enzyme in cellular biosynthesis of the cysteinyl leukotrienes. Prostaglandins Other Lipid Mediat. 2002;68-69:511-520.

67. Söderström M, Mannervik B, Garkov V, Hammarström S. On the nature of leukotriene C4 synthase in human platelets. Arch Biochem Biophys. 1992;294(1):70-74.

68. Ali A, Ford-Hutchinson AW, Nicholson DW. Activation of protein kinase $\mathrm{C}$ down-regulates leukotriene $\mathrm{C} 4$ synthase activity and attenuates cysteinyl leukotriene production in an eosinophilic substrain of HL-60 cells. J Immunol. 1994;153(2):776-788.

69. Esser J, et al. Zymosan suppresses leukotriene $C_{4}$ synthase activity in differentiating monocytes: antagonism by aspirin and protein kinase inhibitors. FASEB J. 2011;25(4):1417-1427.

70. Ahmad S, et al. Phosphorylation of leukotriene C4 synthase at serine 36 impairs catalytic activity. J Biol Chem. 2016;291(35):18410-18418.

71. Lam BK, Penrose JF, Freeman GJ, Austen KF. Expression cloning of a cDNA for human leukotriene $\mathrm{C} 4$ synthase, an integral membrane protein conjugating reduced glutathione to leukotriene A4 Proc Natl Acad Sci U S A. 1994;91(16):7663-7667.

72. Welsch DJ, Creely DP, Hauser SD, Mathis KJ, Krivi GG, Isakson PC. Molecular cloning and expression of human leukotriene-C4 synthase. Proc Natl Acad Sci U S A . 1994;91(21):9745-9749.

73. Jakobsson PJ, Mancini JA, Ford-Hutchinson AW. Identification and characterization of a novel human microsomal glutathione S-transferase with leukotriene $\mathrm{C} 4$ synthase activity and significant sequence identity to 5-lipoxygenaseactivating protein and leukotriene $\mathrm{C} 4$ synthase. J Biol Chem. 1996;271(36):22203-22210.

74. Jakobsson PJ, Mancini JA, Riendeau D, Ford-
Hutchinson AW. Identification and characterization of a novel microsomal enzyme with glutathione-dependent transferase and peroxidase activities. J Biol Chem. 1997;272(36):22934-22939.

75. Scoggan KA, Jakobsson PJ, Ford-Hutchinson AW. Production of leukotriene $\mathrm{C} 4$ in different human tissues is attributable to distinct membrane bound biosynthetic enzymes. J Biol Chem. 1997;272(15):10182-10187.

76. Sjöström M, Jakobsson PJ, Heimburger M, Palmblad J, Haeggström JZ. Human umbilical vein endothelial cells generate leukotriene $\mathrm{C} 4$ via microsomal glutathione S-transferase type 2 and express the CysLT(1) receptor. Eur J Biochem. 2001;268(9):2578-2586.

77. Kanaoka Y, Maekawa A, Penrose JF, Austen KF, Lam BK. Attenuated zymosan-induced peritoneal vascular permeability and IgE-dependent passive cutaneous anaphylaxis in mice lacking leukotriene C4 synthase. J Biol Chem. 2001;276(25):22608-22613.

78. Dvash E, Har-Tal M, Barak S, Meir O, Rubinstein M. Leukotriene C4 is the major trigger of stressinduced oxidative DNA damage. Nat Commun. 2015;6:10112.

79. Jakobsson PJ, Thorén S, Morgenstern R, Samuelsson B. Identification of human prostaglandin $\mathrm{E}$ synthase: a microsomal, glutathione-dependent, inducible enzyme, constituting a potential novel drug target. Proc Natl Acad Sci US A. 1999;96(13):7220-7225.

80. Murakami M, et al. Regulation of prostaglandin E2 biosynthesis by inducible membraneassociated prostaglandin E2 synthase that acts in concert with cyclooxygenase-2. J Biol Chem. 2000;275(42):32783-32792.

81. Samuelsson B, Morgenstern R, Jakobsson PJ. Membrane prostaglandin E synthase-1: a novel therapeutic target. Pharmacol Rev. 2007;59(3):207-224.

82. Jakobsson PJ, Morgenstern R, Mancini J, FordHutchinson A, Persson B. Common structural features of MAPEG - a widespread superfamily of membrane associated proteins with highly divergent functions in eicosanoid and glutathione metabolism. Protein Sci. 1999;8(3):689-692.

83. Penrose JF, et al. Molecular cloning of the gene for human leukotriene C4 synthase. Organization, nucleotide sequence, and chromosomal localization to $5 \mathrm{q} 35$. J Biol Chem. 1996;271(19):11356-11361.

84. Zhao JL, Austen KF, Lam BK. Cell-specific transcription of leukotriene C(4) synthase involves a Kruppel-like transcription factor and Sp1. J Biol Chem. 2000;275(12):8903-8910.

85. Boyce JA, et al. Expression of LTC4 synthase during the development of eosinophils in vitro from cord blood progenitors. Blood.1996;88(11):4338-4347.

86. Riddick CA, Serio KJ, Hodulik CR, Ring WL, Regan MS, Bigby TD. TGF-beta increases leukotriene $\mathrm{C} 4$ synthase expression in the monocyte-like cell line, THP-1. J Immunol. 1999;162(2):1101-1107.

87. Serio KJ, Hodulik CR, Bigby TD. Sp1 and Sp3 function as key regulators of leukotriene C(4) synthase gene expression in the monocytelike cell line, THP-1. Am J Respir Cell Mol Biol. 2000;23(2):234-240. 
88. Hsieh FH, Lam BK, Penrose JF, Austen KF, Boyce JA. T helper cell type 2 cytokines coordinately regulate immunoglobulin E-dependent cysteinyl leukotriene production by human cord bloodderived mast cells: profound induction of leukotriene $\mathrm{C}(4)$ synthase expression by interleukin 4 . JExp Med.2001;193(1):123-133.

89. Schröder O, Sjöström M, Qiu H, Jakobsson PJ, Haeggström JZ. Microsomal glutathione S-transferases: selective up-regulation of leukotriene $\mathrm{C} 4$ synthase during lipopolysaccharideinduced pyresis. Cell Mol Life Sci. 2005;62(1):87-94.

90. Martinez Molina D, et al. Structural basis for synthesis of inflammatory mediators by human leukotriene C4 synthase. Nature. 2007;448(7153):613-616.

91. Ago H, et al. Crystal structure of a human membrane protein involved in cysteinyl leukotriene biosynthesis. Nature. 2007;448(7153):609-612.

92. Rinaldo-Matthis A, et al. Arginine 104 is a key catalytic residue in leukotriene $\mathrm{C} 4$ synthase. J Biol Chem. 2010;285(52):40771-40776.

93. Saino H, et al. The catalytic architecture of leukotriene $\mathrm{C} 4$ synthase with two arginine residues. J Biol Chem. 2011;286(18):16392-16401.

94. Woods JW, Coffey MJ, Brock TG, Singer II, Peters-Golden M. 5-Lipoxygenase is located in the euchromatin of the nucleus in resting human alveolar macrophages and translocates to the nuclear envelope upon cell activation. J Clin Invest. 1995;95(5):2035-2046.

95. Christmas P, Weber BM, McKee M, Brown D, Soberman RJ. Membrane localization and topology of leukotriene C4 synthase. J Biol Chem. 2002;277(32):28902-28908.

96. Mandal AK, et al. The membrane organization of leukotriene synthesis. Proc Natl Acad Sci U S A. 2004;101(17):6587-6592.

97. Horrillo R, et al. 5-Lipoxygenase activating protein signals adipose tissue inflammation and lipid dysfunction in experimental obesity. JImmunol. 2010;184(7):3978-3987.

98. Mothe-Satney I, et al. Adipocytes secrete leukotrienes: contribution to obesity-associated inflammation and insulin resistance in mice. Diabetes. 2012;61(9):2311-2319.

99. Li P, et al. LTB4 promotes insulin resistance in obese mice by acting on macrophages, hepatocytes and myocytes. Nat Med.2015;21(3):239-247.

100. Ying W, et al. Adipose tissue B2 cells promote insulin resistance through leukotriene LTB4/LTB4R1 signaling. JClin Invest. 2017;127(3):1019-1030.

101. Chu J, Praticò D. The 5-lipoxygenase as modulator of Alzheimer's $\gamma$-secretase and therapeutic target. Brain Res Bull. 2016;126(pt 2):207-212.

102. Chu J, Praticò D. 5-Lipoxygenase as an endogenous modulator of amyloid $\beta$ formation in vivo. Ann Neurol. 2011;69(1):34-46.

103. Giannopoulos PF, et al. Gene knockout of 5 -lipoxygenase rescues synaptic dysfunction and improves memory in the triple-transgenic model of Alzheimer's disease. Mol Psychiatry. 2014;19(4):511-518.

104.Giannopoulos PF, et al. Pharmacologic inhibition of 5-lipoxygenase improves memory, rescues synaptic dysfunction, and ameliorates tau pathology in a transgenic model of tauopathy. Biol Psychiatry. 2015;78(10):693-701.
105. Giannopoulos PF, Praticò D. Overexpression of 5-lipoxygenase worsens the phenotype of a mouse model of tauopathy [published online ahead of print November 11, 2017]. Mol Neurobiol. https://doi.org/10.1007/s12035-017-0817-7.

106.Vagnozzi AN, Giannopoulos PF, Praticò D. The direct role of 5-lipoxygenase on tau pathology, synaptic integrity and cognition in a mouse model of tauopathy. Transl Psychiatry. 2017;7(12):1288

107. Vagnozzi AN, Giannopoulos PF, Praticò D. Brain 5-lipoxygenase over-expression worsens memory, synaptic integrity, and tau pathology in the P301S mice. Aging Cell. 2018;17(1):e12695.

108. Marschallinger J, et al. Structural and functional rejuvenation of the aged brain by an approved anti-asthmatic drug. Nat Commun. 2015;6:8466.

109. Di Gennaro A, Haeggström JZ. The leukotrienes: immune-modulating lipid mediators of disease. Adv Immunol. 2012;116:51-92.

110.Colazzo F, Gelosa P, Tremoli E, Sironi L, Castiglioni L. Role of the cysteinyl leukotrienes in the pathogenesis and progression of cardiovascular diseases. Mediators Inflamm. 2017;2017:2432958.

111. Voelkel NF, et al. Inhibition of 5-lipoxygenaseactivating protein (FLAP) reduces pulmonary vascular reactivity and pulmonary hypertension in hypoxic rats. JClin Invest. 1996;97(11):2491-2498.

112. Wright L, Tuder RM, Wang J, Cool CD, Lepley RA, Voelkel NF. 5-Lipoxygenase and 5-lipoxygenase activating protein (FLAP) immunoreactivity in lungs from patients with primary pulmonary hypertension. Am J Respir Crit Care Med. 1998;157(1):219-229.

113. Tian W, et al. Blocking macrophage leukotriene b4 prevents endothelial injury and reverses pulmonary hypertension. Sci Transl Med. 2013;5(200):200ra117.

114. Sharma S, et al. Apolipoprotein A-I mimetic peptide $4 \mathrm{~F}$ rescues pulmonary hypertension by inducing microRNA-193-3p. Circulation. 2014;130(9):776-785.

115. Ee MT, Kantores C, Ivanovska J, Wong MJ, Jain A, Jankov RP. Leukotriene B4 mediates macrophage influx and pulmonary hypertension in bleomycininduced chronic neonatal lung injury. Am J Physiol Lung Cell Mol Physiol. 2016;311(2):L292-L302.

116. Qian J, et al. Leukotriene $B 4$ activates pulmonary artery adventitial fibroblasts in pulmonary hypertension. Hypertension. 2015;66(6):1227-1239.

117. Zhao L, et al. The 5-lipoxygenase pathway promotes pathogenesis of hyperlipidemiadependent aortic aneurysm. Nat Med. 2004;10(9):966-973

118. Cao RY, Adams MA, Habenicht AJ, Funk CD. Angiotensin II-induced abdominal aortic aneurysm occurs independently of the 5-lipoxygenase pathway in apolipoprotein E-deficient mice. Prostaglandins Other Lipid Mediat. 2007;84(1-2):34-42.

119. Houard X, Ollivier V, Louedec L, Michel JB, Bäck M. Differential inflammatory activity across human abdominal aortic aneurysms reveals neutrophil-derived leukotriene B4 as a major chemotactic factor released from the intraluminal thrombus. FASEB J. 2009;23(5):1376-1383.

120. Di Gennaro A, et al. Increased expression of leukotriene $\mathrm{C} 4$ synthase and predominant formation of cysteinyl-leukotrienes in human abdominal aortic aneurysm. Proc Natl Acad Sci U S A. 2010;107(49):21093-21097.

121. Bhamidipati CM, et al. 5-Lipoxygenase pathway in experimental abdominal aortic aneurysms. Arterioscler Thromb Vasc Biol. 2014;34(12):2669-2678.

122. Di Gennaro A, et al. Cysteinyl leukotriene receptor 1 antagonism prevents experimental abdominal aortic aneurysm. Proc Natl Acad Sci U S A. 2018;115(8):1907-1912.

123. Steinhilber D, Hofmann B. Recent advances in the search for novel 5-lipoxygenase inhibitors. Basic Clin Pharmacol Toxicol. 2014;114(1):70-77.

124. Werz O, Gerstmeier J, Garscha U. Novel leukotriene biosynthesis inhibitors (2012-2016) as anti-inflammatory agents. Expert Opin Ther Pat. 2017;27(5):607-620.

125. Musiyenko A, et al. A novel 5-lipoxygenaseactivating protein inhibitor, AM679, reduces inflammation in the respiratory syncytial virusinfected mouse eye. Clin Vaccine Immunol. 2009;16(11):1654-1659.

126. Hutchinson JH, et al. 5-Lipoxygenase-activating protein inhibitors: development of 3-[3-tertbutylsulfanyl-1-[4-(6-methoxy-pyridin-3-yl)benzyl]-5-(pyridin-2-ylmethoxy)-1H-indol-2-yl]2,2-dimethyl-propionic acid (AM103). JMed Chem. 2009;52(19):5803-5815.

127. Serhan CN. Pro-resolving lipid mediators are leads for resolution physiology. Nature. 2014;510(7503):92-101.

128. Lehmann C, et al. Lipoxin and resolvin biosynthesis is dependent on 5-lipoxygenase activating protein. FASEB J. 2015;29(12):5029-5043.

129. Werz O, et al. Human macrophages differentially produce specific resolvin or leukotriene signals that depend on bacterial pathogenicity. Nat Commun. 2018;9(1):59.

130. Fredman G, et al. An imbalance between specialized pro-resolving lipid mediators and pro-inflammatory leukotrienes promotes instability of atherosclerotic plaques. Nat Commun. 2016;7:12859.

131. Pace S, et al. Androgen-mediated sex bias impairs efficiency of leukotriene biosynthesis inhibitors in males. JClin Invest. 2017;127(8):3167-3176.

132. Orning L, Krivi G, Fitzpatrick FA. Leukotriene A4 hydrolase. Inhibition by bestatin and intrinsic aminopeptidase activity establish its functional resemblance to metallohydrolase enzymes. J Biol Chem. 1991;266(3):1375-1378.

133. Yuan W, Wong C-H, Haeggström JZ, Wetterholm A, Samuelsson B. Novel tight-binding inhibitors of leukotriene A4 hydrolase. J Am Chem Soc. 1992;114:6552-6553.

134. Hogg JH, et al. Amino hydroxamic acids as potent inhibitors of LTA4 hydrolase. Bioorg Med Chem. 1995;3(10):1405-1415.

135. Penning TD. Inhibitors of leukotriene A4 (LTA4) hydrolase as potential anti-inflammatory agents. Curr Pharm Des. 2001;7(3):163-179.

136. Sandanayaka V, et al. Discovery of 4-[(2S)-2\{[4-(4-chlorophenoxy)phenoxy]methyl\}-1pyrrolidinyl]butanoic acid (DG-051) as a novel leukotriene A4 hydrolase inhibitor of leukotriene B4 biosynthesis. J Med Chem. 2010;53(2):573-585.

137. Whittle BJ, et al. Attenuation of inflammation and cytokine production in rat colitis by a novel selec- 


\section{REVIEW SERIES: LIPID MEDIATORS OF DISEASE}

tive inhibitor of leukotriene A4 hydrolase. $\mathrm{Br} \mathrm{J}$ Pharmacol. 2008;153(5):983-991.

138. Rao NL, et al. Anti-inflammatory activity of a potent, selective leukotriene A4 hydrolase inhibitor in comparison with the 5-lipoxygenase inhibitor zileuton. J Pharmacol Exp Ther. 2007;321(3):1154-1160.

139. Rao NL, et al. Leukotriene A(4) hydrolase inhibition attenuates allergic airway inflammation and hyperresponsiveness. Am J Respir Crit Care Med. 2010;181(9):899-907.

140. Elborn JS, et al. Phase I studies of acebilustat: biomarker response and safety in patients with cystic fibrosis. Clin Transl Sci. 2017;10(1):28-34.

141. Bhatt L, Roinestad K, Van T, Springman EB. Recent advances in clinical development of leukotriene B4 pathway drugs. Semin Immunol. 2017;33:65-73.

142.Stsiapanava A, et al. Binding of Pro-Gly-Pro at the active site of leukotriene A4 hydrolase/ aminopeptidase and development of an epoxide hydrolase selective inhibitor. Proc Natl Acad Sci U S A. 2014;111(11):4227-4232.
143. Devi NS, Doble M. Leukotriene c4 synthase: upcoming drug target for inflammation. Curr Drug Targets. 2012;13(8):1107-1118.

144. Ago H, et al. A leukotriene C4 synthase inhibitor with the backbone of 5-(5-methylene-4-oxo4,5-dihydrothiazol-2-ylamino) isophthalic acid. JBiochem. 2013;153(5):421-429.

145. Kleinschmidt TK, et al. Tandem benzophenone amino pyridines, potent and selective inhibitors of human leukotriene C4 synthase. J Pharmacol Exp Ther. 2015;355(1):108-116.

146. Maekawa A, Kanaoka Y, Xing W, Austen KF. Functional recognition of a distinct receptor preferential for leukotriene $\mathrm{E} 4$ in mice lacking the cysteinyl leukotriene 1 and 2 receptors. Proc Natl Acad Sci U S A. 2008;105(43):16695-16700.

147. Maekawa A, Balestrieri B, Austen KF, Kanaoka Y. GPR17 is a negative regulator of the cysteinyl leukotriene 1 receptor response to leukotriene D4. Proc Natl Acad Sci U S A. 2009;106(28):11685-11690.

148. Kanaoka Y, Maekawa A, Austen KF. Identification of GPR99 protein as a potential third cysteinyl leukotriene receptor with a preference for leukotriene E4 ligand. J Biol Chem. 2013;288(16):10967-10972.

149. Bankova LG, et al. Leukotriene E4 elicits respiratory epithelial cell mucin release through the G-protein-coupled receptor, GPR99. Proc Natl Acad Sci U S A. 2016;113(22):6242-6247.

150. Tang F, et al. Cysteinyl leukotrienes mediate lymphokine killer activity induced by NKG2D and IL-15 in cytotoxic T cells during celiac disease. JExp Med. 2015;212(10):1487-1495.

151. Kita Y, Takahashi T, Uozumi N, Nallan L, Gelb $\mathrm{MH}$, Shimizu T. Pathway-oriented profiling of lipid mediators in macrophages. Biochem Biophys Res Commun. 2005;330(3):898-906.

152. Lukic A, et al. GM-CSF- and M-CSF-primed macrophages present similar resolving but distinct inflammatory lipid mediator signatures. FASEB J. 2017;31(10):4370-4381.

153. Provost P, Dishart D, Doucet J, Frendewey D, Samuelsson B, Rådmark O. Ribonuclease activity and RNA binding of recombinant human Dicer. EMBO J. 2002;21(21):5864-5874. 